\title{
Red Plaque of the Breast: Think Of Paget Disease
}

\section{Kaoutar Laamari*, Zakia Douhi, Sara Elloudi, Hanane Baybay, Fatima Zahra Mernissi}

Department Of Dermatology, University Hospital Hassan II Fez, Morocco

* Corresponding Author: Kaoutar Laamari, Department of Dermatology and Venerology, University Hospital Hassan II Fez, Morocco. Email: kaoutar.laamari1@gmail.com

Received date: December 19, 2019; Accepted date: January 02, 2020; published date: January 10, 2020

Citation: Kaoutar L, Zakia D, Sara E, Hanane B, Fatima ZM (2020) Red Plaque of the Breast: Think Of Paget Disease. J Clinical Research and Reports, 2(1); DOI:10.31579/jcrr.2020/010

Copyright: () 2020 Kaoutar L. This is an open access article distributed under the Creative Commons Attribution License, which permits unrestricted use, distribution, and reproduction in any medium, provided the original work is properly cited.

An 80-year-old patient with 7-year-old erythematous lesion gradually increasing in pain size. Clinical examination revealed a well-defined erythematous patch with irregular contours surmounted by haemorrhagic crusts with destruction of the nipple. There was no breast flow or palpable nodule and no lymph node involvment. Histological examination revealed a Paget's disease with overexpression of cytokeratin 7. The mammogram echo showed a focus of suspicious-looking micro-calcifications. Nipple biopsy was performed. The pathological study found high grade intracanal carcinoma, with nipple Paget's disease.

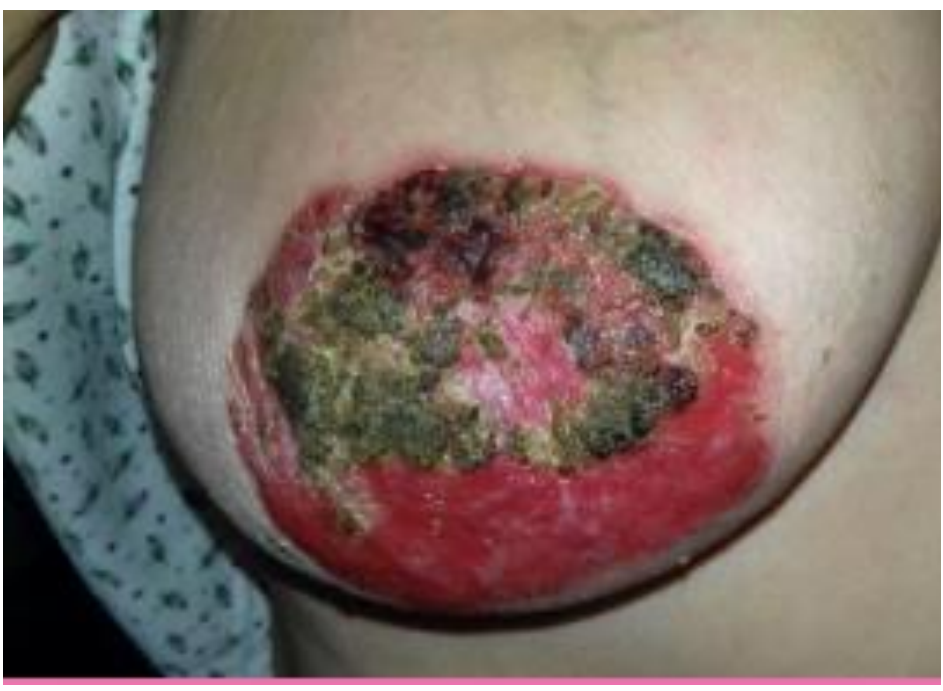

Paget's disease was first described by Sir Paget in 1874 as an eczema-like lesion of the nipple linked to an underlying cancer. This is a rare entity that affects only 1 to $4 \%$ of breast cancers. $(1,2)$ It mainly affects menopausal women with an average age of 62.6 years. No clinical or epidemiological factors are recognized as predisposing to the development of this disease. Clinically, Paget's mammary disease manifests itself as a scaly, thickened, sometimes pigmented, patchy plaque with irregular edges. This lesion can be limited to the nipple or extended to the areola and even to the surrounding skin. (3) In the case of an eczematous lesion, the main differential diagnosis of Paget's disease is nipple eczema. But unilaterality, scalability and lack of response to corticosteroid therapy help to correct the diagnosis. Other differential diagnoses, such as psoriasis, superficial basal cell carcinoma and melanoma, may also be discussed and only histology will confirm the diagnosis. Mastectomy has long been considered the appropriate treatment because of its frequent association with multifocal or multicenter breast cancer. Currently, the majority of teams adopt conservative treatment.

\section{References}

1. Chaudray MA, Millis RR, Lane EB, Miller NA (1986) Paget's disease of the nipple : a ten year review including clinical, pathological, and immunohistochemical findings. Breast CancerRes. Treat.

2. Chen C, Sun L, Anderson BO (2006) Paget Disease of the breast : Changing patterns of incidence, clinical presentation, and treatment in the US. Cancer, 107 (7): 139-46 2. 2 ; 144858

3. Ward KA, Burton JL (1997) Dermatologic Disease of the breast in young women. Clin. Dermatol; 15(1): 45-5 